\title{
Can HCQ Be Considered a "Safe Weapon" for COVID-19 in the Indian Population?
}

\author{
Pugazhenthan Thangaraju ${ }^{1}$ (ID $\cdot$ Nanditha Venkatesan $^{2} \cdot$ Sajitha Venkatesan $^{3}$. \\ Meenalotchini Prakash Gurunthalingam ${ }^{1}$ • Eswaran Thangaraju ${ }^{4}$
}

Accepted: 1 July 2020 / Published online: 10 July 2020

(C) Springer Nature Switzerland AG 2020

\begin{abstract}
With no drugs currently approved for treatment and cure of COVID-19 (coronavirus disease 2019), hydroxychloroquine is one of the many first-line drugs used in the management. However, given the life-threatening adverse effects of HCQ that have been reported, its use as a prophylactic treatment remains debated. HCQ has long been used in India for the treatment of malaria, autoimmune and inflammatory diseases, and even type 2 diabetes mellitus recently. We aimed to review existing literature and relevant Web sites regarding the safety profile of HCQ in the Indian subcontinent. A non-systematic critical analysis of all published literature/studies focused on the Indian population, recording on the use of HCQ for various indications up till April 2020 was done and frequency of occurrence of HCQ related life-threatening and cardiac side effects were noted. Results from PubMed database showed an incidence of $0.6 \%$ of cardiac-related side effects and $7.42 \%$ of other self-limiting and minor side effects among the Indian population on HCQ. Considering its minimal risk and favorable safety profile, cost-effectiveness, availability, and affordability in India, the use of hydroxychloroquine in the fight against COVID-19 appears rationale. Following the results of our study, we hypothesize that Indians might be less likely to suffer from cardiac-related side effects given their genetic make-up. However, this would need further studies, clinical trials, and a pharmacogenomic understanding of the subject.
\end{abstract}

Keywords Hydroxychloroquine $\cdot$ Chloroquine $\cdot$ Cardiac side effects $\cdot$ India

\section{Introduction}

The World Health Organization declared the coronavirus disease 2019 (COVID-19) a pandemic on 11 March 2020 [1]. Given the nature of this global public health emergency, multiple drugs have been tried in the battle against this disease. Some of these include antimalarial drugs such as hydroxychloroquine, azithromycin, various anti-viral

This article is part of the Topical Collection on Covid-19

Pugazhenthan Thangaraju

drpuga123@gmail.com

1 Department of Pharmacology, All India Institute of Medical Sciences, Raipur, India

2 All India Institute of Medical Sciences, Raipur, India

3 Department of Microbiology, All India Institute of Medical Sciences, Raipur, India

4 AKT Memorial College of Engineering and Technology, Kallakurichi, Tamilnadu, India medications, and recently, even host-directed therapies [2-5]. Although a majority of these drugs have been cited as potential candidates, their clinical efficacy and safety profile have not been completely evaluated.

Chloroquine, an age old member of the WHO list of Essential medicines, has been studied extensively for its immunomodulatory properties and antiviral mechanisms [6]. Hydroxychloroquine is one such formulation which has come into light for its use in COVID-19 treatment given its proven efficacy in both laboratory and in vivo studies [7]. It has been observed to inhibit ACE2 receptor-mediated entry of the SARS-CoV2 virus through various actions such as raising of intravesicular $\mathrm{pH}$, inhibiting lysosomal activity, and affecting antigen processing [8-10]. It has strong anti-inflammatory and immunomodulatory properties that are beneficial against the surge of cytokines that occur in the background of COVID-19 infection [7-11].

The reports of adverse effects, both minor and major, appear to be the limiting factor against the use of this drug [12]. Minor side effects range from nausea, vomiting, diarrhea, constipation, skin rash and itching, cutaneous hyperpigmentation, 
gastritis to name a few, while major side effects include retinal toxicity, maculopathies, acute pulmonary edema, reversible heart failure, and cardiac arrhythmias (QTc prolongation) [13]. Therefore, precautions needed while using these drugs include frequent monitoring of hematological parameters, serum electrolytes, blood sugar levels, renal and hepatic function tests, routine electrocardiography prior to initiation of the drug, and visual acuity testing.

Sudden deaths reported in the West, following the administration of HCQ, are mainly due to the QT interval prolongation and torsades de pointes (TdP) in susceptible individuals [13]. The risk of TdP is not a linear function of basal QTc or drug-induced prolongation in QTc interval. Moreover, not all patients with drug-induced QTc prolongation will develop TdP. This side effect is rare, but co-prescription of other drugs such as azithromycin (which is also being recommended for the treatment of COVID-19) could amplify this risk [14, 15].

Although there are sporadic case reports of sudden deaths, cardiomyopathy, and reversible heart failure, a large metaanalysis of HCQ use in rheumatoid arthritis, contrary to popular belief, pointed to reduced cardiovascular risk [16, 17].

Acquired long QT syndrome (aLQTS), also known as drug-induced LQTS, has been studied to look for genetic variants associated with the condition. A number of studies have strongly supported the idea that variation, not only in $\mathrm{KCNH} 2$ (which codes for Potassium voltage gated channel) but also in other cardiac ion channels and associated genes, may predispose individuals to acquired LQTS $[18,19]$. However, a lot of this data has been generated from Western literature.

Firstly, data regarding response and reaction of Indians to HCQ is lacking despite its widespread use in malaria, autoimmune disorders, inflammatory conditions, dermatological complaints, and even type 2 diabetes mellitus. Secondly, mutations and variants in the channels in an Indian community based-sample will help bridge the gap between genetic factors, influence of the race thereby and other possible drug interaction and reactions.

\section{Advisory for HCQ Prophylaxis in HR Population as Declared by ICMR}

The measures to contain the spread of COVID-19 such as social distancing, hand hygiene, surveillance, and isolation of persons suspected or confirmed to have infection have been considered as mainstay. Government authorities have issued guidelines to healthcare workers and public, advising strict adherence to above measures and acknowledge the limited role of drugs in the treatment and prophylaxis.

The use of HCQ and its efficacy in the treatment against SARS-CoV2 arebased on laboratory studies, pre-clinicaldata and risk-benefit considerations. The Indian National Taskforce for COVID-19 recommends the use of HCQ for prophylaxis of SARS-CoV2 infection for "all asymptomatic healthcare workers (containment and treatment), asymptomatic healthcare workers (non-COVID hospitals/non-COVID areas of COVID hospitals/blocks), and the asymptomatic frontline workers (surveillance workers-containmentzones and paramilitary/police personnel involved in COVID-19related activities) - $400 \mathrm{mg}$ twice a day on day $1,400 \mathrm{mg}$ once weekly for the next 7 weeks, taken with meals and asymptomatic household contacts of laboratory confirmed cases$400 \mathrm{mg}$ twice a day on day 1 , followed by $400 \mathrm{mg}$ once weekly forthenext3weekstakenwithmeals"[20].However,thedrugis contraindicated for prophylaxis in children under 15 years of age, known cases of retinopathy, hypersensitivity to the drug and other 4-aminoquinoline compounds, G6PD deficiency, and any preexisting cardiomyopathy and cardiac rhythm disorders. With available evidence for its safety and beneficial effect as a prophylactic drug againstSARS-COV-2 during the earlier recommended 8-week period, the experts further recommended for its use beyond 8 weeks on weekly dosage with strictmonitoring of clinicalandECG parameters which would also ensure that the therapy is given under supervision.

\section{Methods}

A PubMed Database search was conducted. The search strategy was carried out using keywords such as "Hydroxychloroquine," "Chloroquine," "Cardiac side effects," and "India."

Our search strategy was ( ( (Chloroquine OR Hydroxychloroquine)) AND (Deaths OR Fatal outcome OR, Cardiac OR heart OR side-effects OR side-effect OR side effects OR adverse event OR adverse reaction OR arrhythmia OR block OR QT prolongation OR QTc Prolongation)) AND India).

We included clinical trials, research studies, case reports, and randomized control trials that employed the use of HCQ/ $\mathrm{CQ}$ at any point in the treatment of patients of Indian origin. In addition, we also searched the references section of the screened articles to extract information regarding Indian articles of relevance.

\section{Study Selection}

Following our search strategy, the results were screened in a stepwise manner. Title screening, followed by relevant abstract, filtering, and finally, a full-text screening was done as per inclusion and exclusion criteria.

\section{Inclusion Criteria}

- Patients: Indian patients both adult and pediatric population 
- Intervention: $\mathrm{HCQ} / \mathrm{CQ}$ used at any point in the treatment of any disease condition

- Type of study: Clinical trials, research studies, case reports and randomized control trials

\section{Exclusion Criteria}

- Review articles by Indian authors citing data not of Indian origin.

- Meta-analyses by Indian authors citing data not of Indian origin.

- Comments by Indian authors on safety profile with data from other countries.

\section{Data Extraction (Selection and Coding)}

Three reviewers independently screened titles and abstract of relevant search results that met the inclusion criteria prior to screening full-text papers. Details that were extracted to included author and journal details, year of publication, sample size, age, sex, indication for rational use of hydroxychloroquine, duration for treatment, the number of patients that reported various minor side effects, the number of patients that reported major side effects, and deaths, if any, during the period of the study.

Our focus, however, was on side effects observed in the Indian population with HCQ use. Once this data was retrieved, we calculated the total number of subjects across all reports that received HCQ and the proportion which developed both minor and serious adverse reactions.

\section{Statistical Analysis}

The data were extracted in Google Sheets and Excel in numbers and converted later to percentages.

\section{Results}

With our aforementioned search strategy and a couple of other similar searches that were tried, we screened a total of 317 articles (Fig. 1). Of these, 105 articles were title-screened. A total of 3123 Indian patients were treated with either HCQ or CQ for different indications and at different doses, for different durations.

We recorded a total 253 adverse reactions that were reported in these articles. Adverse reactions were further grouped as non-cardiac and cardiac. Non-cardiac reactions were 232 (Fig. 2) in all and included minor reversible ones such as urticaria, itching, epigastric pain, nausea, diarrhea, constipation, and also some that were potentially life-threatening, such as psychosis, mania, retinal toxicity, hypoglycemia, methemoglobinemia, extrapyramidal syndromes, and Parkinsonism, to name a few. Cardiac-related adverse effects (Fig. 3) were 19 in all, 13 QTc prolongations, 2 chest pains, 1 cardiovascular collapse, 1 recurrent syncopal attack, 1 acute pulmonary edema, and 1 cardiomyopathy. Two deaths were reported whose causes were not mentioned or known (Table 1).

\section{Discussion}

Hydroxychloroquine came as a beacon of hope in the battle against the COVID-19 pandemic. Given its dubious safety profile, there are two schools of thought about using HCQ for chemoprophylaxis. However, we believe that there might be more to the story than that meets the eye. It might not be prudent to replicate the number of adverse reactions observed in Western population and superimpose them on the Indian patient.

The Indian portal for reporting adverse events, also known as PvPI (Pharmaco-vigilance Programme of India) under the Indian Pharmacopeia Commission, Ghaziabad, was checked prior to the start of the search across PubMed for details regarding the ADRs developing from administration of $\mathrm{CQ} /$ HCQ. However, we could not get any information available in the open public database.

We also searched Vigiaccess [13], the online database for ICSRs (Individual case Safety Reports) for information regarding geographic distribution of ADRs. However, it only gave data in broad headings of Africa, the Americas, Asia, Europe, and Oceania, thereby limiting our data collection. It was interesting to note that Americas noted $56 \%$ of the ADRs from use of hydroxychloroquine, Europe 27\%, and Asia $14 \%$. However, it should be borne in mind that underreporting could also be an attributing factor to this.

The latest revised advisory released by Indian Council of Medical Research (ICMR) states that HCQ prophylaxis among $1323 \mathrm{HCWs}$ indicated mild adverse effects such as nausea $(8.9 \%)$, abdominal pain $(7.3 \%)$, vomiting (1.5\%), hypoglycemia $(1.7 \%)$, and cardiovascular effects $(1.9 \%)$. However, as per the data from the PvPI, there have been 214 reported instances of adverse drug reactions associated with prophylactic HCQ use. Of these, 7 were serious individual case safety reports with prolongation of the QT interval on ECG in 3 cases. Then again, the denominator for this value, that is, the overall number of healthcare workers who took prophylactic HCQ, is not available. Details regarding any underlying contraindications were also not mentioned.

Including the ICMR data, $1.9 \%$ of the $1323 \mathrm{HCWs}$ who took HCQ as prophylaxis developed cardiovascular risks ( $n=$ 25). Summing up both these samples $(1323+3123)$, we get a total sample size of 4446 individuals who have been subjected 
Fig. 1 Selection of studies

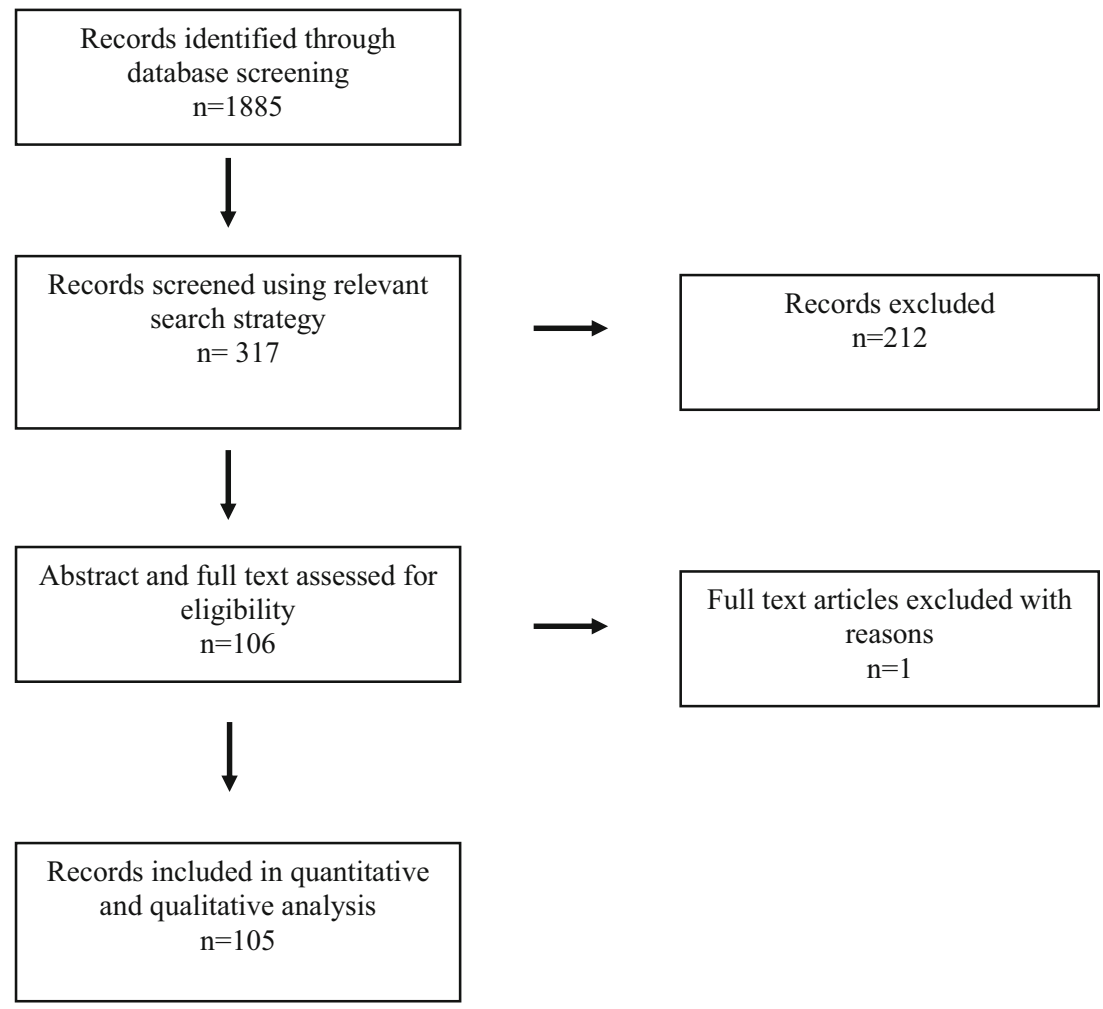

to HCQ, both in therapeutic and prophylactic doses. About $0.98 \%$ is at risk of developing cardiovascular side effects according to this number.

Based on the evidence released by ICMR and PvPI, they have opined that HCQ is relatively safe, when certain contraindications are avoided, and that it has considerable benefit as a prophylactic option. The advisory recommends HCQ

\section{Non-cardiac and minor reaction Unaffected \\ - Cardiac-related reactions}

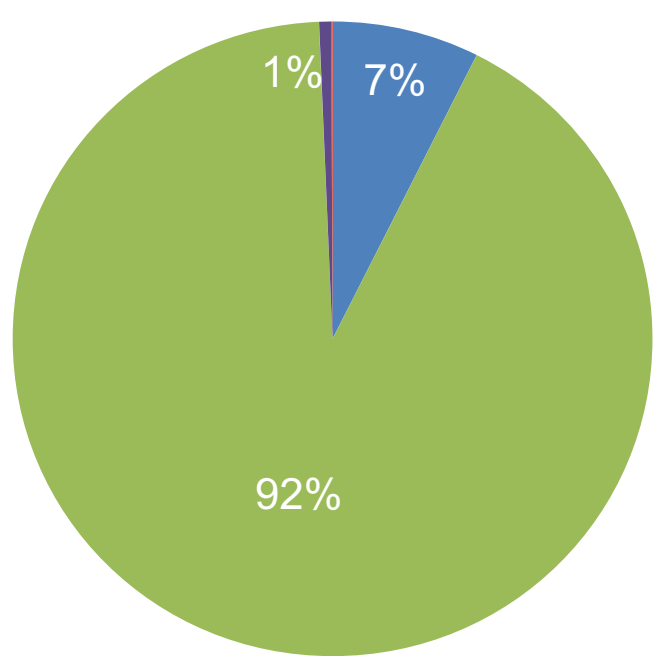

Fig. 2 Proportion of reactions both cardiac and non-cardiac among all patients on HCQ administration under strict medical supervision and informed consent.

Limitations faced during data collection included the following:

- A number of adverse events were mentioned, but details of the same were not provided in the studies. So, data regarding types of minor reactions could not be extracted

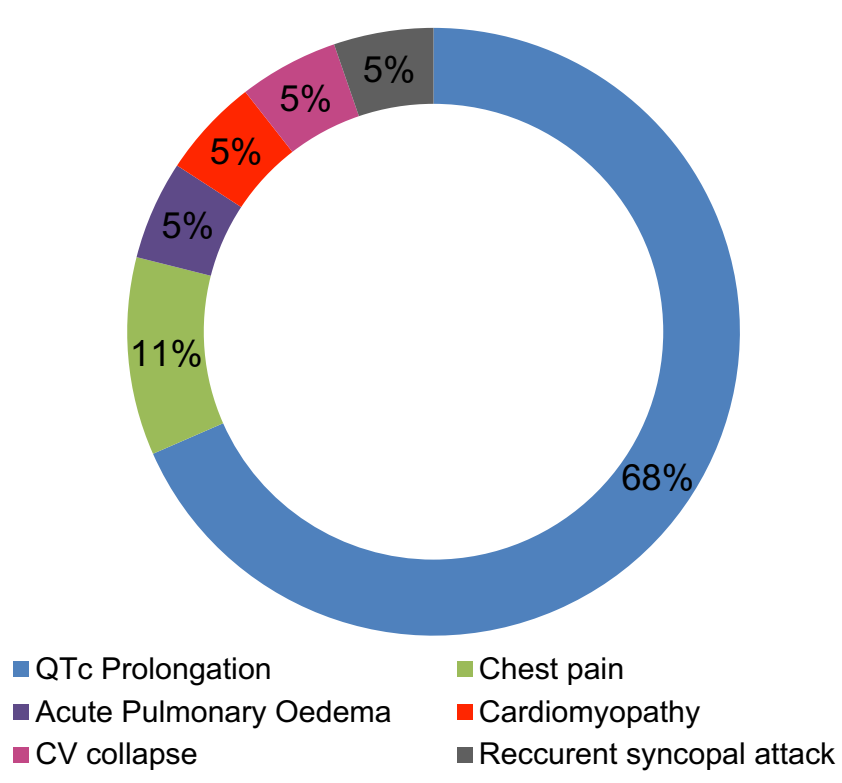

Fig. 3 Frequency of various cardiac side effects following HCQ use 
Table 1 Published literature with cardiac pathology

\begin{tabular}{|c|c|c|c|}
\hline Title of study & Author & $\begin{array}{l}\text { Sample } \\
\text { size }\end{array}$ & Reported ADR \\
\hline $\begin{array}{l}\text { Cardiovascular collapse following small } \\
\text { dose of chloroquine in healthy young } \\
\text { adult [21] }\end{array}$ & $\begin{array}{l}\text { Sogani RK, Sharma DK, } \\
\text { Gupta V, } 1986\end{array}$ & 1 & $\begin{array}{l}\text { Cardiovascular collapse } \\
\quad 1\end{array}$ \\
\hline $\begin{array}{l}\text { Hydroxychloroquine-induced restrictive } \\
\text { cardiomyopathy: a case report [22] }\end{array}$ & $\begin{array}{l}\text { MU Dogar, NN Shah, S } \\
\text { Ishtiaq et al., } 2018\end{array}$ & 1 & Cardiomyopathy 1 \\
\hline $\begin{array}{l}\text { Hydroxychloroquine-induced } \\
\text { phospholipidosis in a case of SLE: the } \\
\text { wolf in zebra clothing [23] }\end{array}$ & $\begin{array}{l}\text { SR Khubchandani, LS } \\
\text { Bichle, } 2013\end{array}$ & 1 & Chest pain 1 \\
\hline $\begin{array}{l}\text { Efficacy and safety of hydroxychloroquine } \\
\text { in the treatment of type } 2 \text { diabetes } \\
\text { mellitus: a double-blind, randomized } \\
\text { comparison with pioglitazone [24] }\end{array}$ & $\begin{array}{l}\text { A Pareek, } \mathrm{N} \\
\text { Chandurkar, N } \\
\text { Thomas et al., } 2014\end{array}$ & 135 & $\begin{array}{l}\text { Chest pain } 1 \\
\text { Acute pulmonary edema } \\
\quad 1\end{array}$ \\
\hline $\begin{array}{l}\text { Recurrent syncopal attacks in a lady with } \\
\text { rheumatoid arthritis [25] }\end{array}$ & $\begin{array}{l}\text { S Kubba, HK Bali, A } \\
\text { Bahl, S Nand Kumar, } \\
2004\end{array}$ & 1 & $\begin{array}{l}\text { Recurrent syncopal } \\
\text { attack (?Heart block } \\
\text { due to cardio-toxicity) } \\
1\end{array}$ \\
\hline $\begin{array}{l}\text { Comparison of the safety and efficacy of } \\
\text { fixed-dose combination of arterolane } \\
\text { maleate and piperaquine phosphate with } \\
\text { chloroquine in acute, uncomplicated } \\
\text { Plasmodium vivax malaria: a phase III, } \\
\text { multicentric, open-label study [26] }\end{array}$ & $\begin{array}{l}\text { N Valecha, D } \\
\text { Savargaonkar, B } \\
\text { Srivastava et al., } 2016\end{array}$ & 158 & QT prolongation 5 \\
\hline $\begin{array}{l}\text { Tafenoquine plus chloroquine for the } \\
\text { treatment and relapse prevention of } \\
\text { Plasmodium vivax malaria } \\
\text { (DETECTIVE): a multicentre, } \\
\text { double-blind, randomized, phase } 2 \mathrm{~b} \\
\text { dose-selection study [27] }\end{array}$ & $\begin{array}{l}\text { Llanos-Cuentas A, } \\
\text { Lacerda MV, } \\
\text { Rueangweerayut R } \\
\text { et al., } 2014\end{array}$ & 54 & $\begin{array}{l}\text { QT prolongation } 2 \text { (race } \\
\text { unknown) }\end{array}$ \\
\hline $\begin{array}{l}\text { Pyronaridine-artesunate versus } \\
\text { chloroquine in patients with acute } \\
\text { Plasmodium vivax malaria: a } \\
\text { randomized, double-blind, } \\
\text { non-inferiority trial [28] }\end{array}$ & $\begin{array}{l}\text { Y Poravuth, D Socheat, } \\
\text { R Rueangweerayut } \\
\text { et al., } 2011\end{array}$ & 41 & $\begin{array}{l}\text { Death 1, QT } \\
\quad \text { prolongation } 6 \text { (all } \\
\text { races included) }\end{array}$ \\
\hline $\begin{array}{l}\text { A randomized, double-blind, } \\
\text { parallel-group, comparative safety, and } \\
\text { efficacy trial of oral co-artemether ver- } \\
\text { sus oral chloroquine in the treatment of } \\
\text { acute uncomplicated Plasmodium } \\
\text { falciparum malaria in adults in India } \\
\text { [29] }\end{array}$ & $\begin{array}{l}\text { NA Kshirsagar, NJ } \\
\text { Gogtay, NS Moorthy } \\
\text { et al., } 2000\end{array}$ & 90 & $\begin{array}{l}\text { Death } 1 \text { (cause } \\
\text { unknown) }\end{array}$ \\
\hline
\end{tabular}

from these papers. Many papers quoted these reactions as self-limiting and deemed it unimportant to report.

- Multi-centric and multi-ethnic cohorts that were used for RCTs did not mention the race of the individual whose ADR was recorded. We have, however, included the number of events mentioned because we believed it was better to err on the higher side (for example, this was true for one of the deaths that were reported by a multi-centric study conducted across Asia, Table 1).

- Similarly, the case report that mentioned recurrent syncopal attacks as a drug reaction lacks the proof for the same. It was hypothesized that it could be from the disease process (rheumatoid arthritis - nodule in the heart tissue, in this case) or from cardiotoxicity due to the drug. We, however, included the event in the study, in an attempt to be more inclusive of possible adverse reactions (Table 1)

- We also found an article that reported ADRs of many different drugs in a tertiary care during a specified period of time, but we could not use this article due to lack of information on the denominator, that is, the total number of patients receiving the drug in the study setup.

- Lastly, an important data that was elusive in these studies was details pertaining to demographic variables, comorbidities, any underlying structural heart diseases, history of co-administration with other QT interval prolonging medications such as macrolides, quinolones, antihistaminics, antiviral, antiarrhythmic, or antifungal drugs.

- Apart from these limitations, it is important to note that chloroquine is more widely available in the Indian context 
given its continued use against malaria, while HCQ is more often prescribed for inflammatory conditions. Therefore, this further impedes our data collection with reference to HCQ adverse effects.

\section{Conclusion}

While several intervention trials are currently underway with HCQ in COVID-19 patients at different doses in the international level, we believe it would be wise to conduct similar large-scale trials on both COVID-19 patients and others taking HCQ for multiple other indications among the Indian patient subgroup. Also, a pharmacogenomic study to understand the interplay of HCQ and genetic factors will throw light on Indians and their propensity to develop cardiac morbidities and other potentially life-threatening side effects following the administration of HCQ.

In the possibility that race might prove to be protective against the ill-effects of HCQ, it will help in allaying the fear among the public and putting to rest any panic regarding the use of the drug in prophylaxis against COVID-19. However, in the absence of the same, physicians must be urged to be more cautious and watchful during the period of drug administration and carry out the required monitoring.

\section{Compliance with Ethical Standards}

Conflict of Interest The authors declare that they have no conflict of interest.

Ethical Approval This article does not contain any studies with human participants or animals performed by any of the authors.

Informed Consent Not applicable. This article does not contain any studies with human participants or animals performed by any of the authors.

\section{References}

1. WHO Director-General's opening remarks at the media briefing on COVID-19 - 11 March 2020. https://www.who.int/dg/speeches/ detail/who-director-general-s-opening-remarks-atthe-mediabriefing-on-covid-19\%2D\%2D-11-march-2020

2. Morse JS, Lalonde T, Xu S, Liu WR. Learning from the past: possible urgent prevention and treatment options for severe acute respiratory infections caused by $2019-\mathrm{nCoV}$. Chembiochem. 2020;21(5):730-8.

3. Lai CC, Liu YH, Wang CY, et al. Asymptomatic carrier state, acute respiratory disease, and pneumonia due to severe acute respiratory syndrome coronavirus 2 (SARS-CoV-2): Facts and myths [published online ahead of print, 2020 Mar 4]. J Microbiol Immunol Infect. 2020;S1684-1182(20):30040-2.

4. Singh AK, Singh A, Shaikh A, Singh R, Misra A. Chloroquine and hydroxychloroquine in the treatment of COVID-19 with or without diabetes: a systematic search and a narrative review with a special reference to India and other developing countries. Diabetes Metab Syndr. 2020;14(3):241-6.

5. Zumla A, Hui DS, Azhar EI, Memish ZA, Maeurer M. Reducing mortality from 2019-nCoV: host-directed therapies should be an option. Lancet. 2020;395(10224):e35-6.

6. Savarino A, Boelaert JR, Cassone A, Majori G, Cauda R. Effects of Chloroquine on viral infections: an old drug against today's diseases? Lancet Infect Dis. 2003;3:722-7.

7. Liu J, Cao R, Xu M, Wang X, Zhang H, Hu H. Hydroxychloroquine, a less toxic derivative of chloroquine, is effective ininhibiting SARS-CoV-2 infection in vitro. Cell Discov. 2020;6:16.

8. Wang M, Cao R, Zhang L, Yang X, Liu J, Xu M. Remdesivir and chloroquine effectively inhibit the recently emerged novel coronavirus (2019-nCoV) in vitro. Cell Res. 2020.

9. Colson P, Rolain JM, Raoult D. Chloroquine for the 2019 novel coronavirus SARS-CoV-2. Int J Antimicrob Agents. 2020;55(3): 105923. https://doi.org/10.1016/j.ijantimicag.2020.105923.

10. Zhou N, Pan T, Zhang J, Li Q, Zhang X, Bai C. Glycopeptide antibiotics potently inhibit cathepsin $\mathrm{L}$ in the late endosome/ lysosome and block the entry of Ebola virus, middle east respiratory syndrome coronavirus (MERS-CoV), and severe acute respiratory syndrome coronavirus (SARS-CoV). J Biol Chem. 2016;291: $9218 \mathrm{e} 32$.

11. Colson P, Rolain JM, Lagier JC, Brouqui P, Raoult D. Chloroquine and hydroxychloroquine as available weapons to fight COVID-19. Int J Antimicrob Agents. 2020;55(4):105932. https://doi.org/10. 1016/j.ijantimicag.2020.105932.

12. Pereira BB. Challenges and cares to promote rational use of chloroquine and hydroxychloroquine in the management of coronavirus disease 2019 (COVID-19) pandemic: a timely review. J Toxicol Environ Health B Crit Rev. 2020;12:1-5.

13. World Adverse reaction data. http://www.vigiaccess.org/. Retreived on 13-05-2020.

14. Chloroquine US prescribing information. https://www.accessdata. fda.gov/ drugsatfda_docs/label/2017/009768s037s045s047lbl.pdf. Retreived on 13-05-2020.

15. Chloroquine US prescribing information. https://www.accessdata. fda.gov/ drugsatfda_docs/label/ 2017/006002s044lbl.pdf. Retreived on 13-05-2020.

16. Liu D, Li X, Zhang Y, Kwong JSW, Li L, Zhang Y, et al. Chloroquine and hydroxychloroquine are associated with reduced cardiovascular risk: a systematic review and meta-analysis. Drug Des Devel Ther. 2018;12:1685-95.

17. Babary H, Liu X, Ayatollahi Y, Chen XP, Doo L, Uppaluru LK, et al. Favorable effects of hydroxychloroquine on serum low density lipid in patients with systemic lupus erythematosus: a systematic review and meta-analysis. Int J Rheum Dis. 2018;21(1):84-92.

18. Yang P, Kanki H, Drolet B, Yang T, Wei J, Viswanathan PC, et al. Allelic variants in long-QT disease genes in patients with drugassociated torsades de pointes. Circulation. 2002;105:1943-8.

19. Kannankeril PJ, Roden DM, Norris KJ, Whalen SP, George AL Jr, Murray KT. Genetic susceptibility to acquired long QT syndrome: pharmacologic challenge in first-degree relatives. Heart Rhythm. 2005;2:134-40.

20. ICMR recommendation on prophylaxis. https://www.mohfw.gov. in/pdf/ Advisory on the use of Hydroxychloroquin as prophylaxis for SARSCoV2 infection.pdf, https://www.icmr.gov.in/pdf/covid/ techdoc/V5_Revised_advisory_on_the_use_of_HCQ_SARS CoV2_infection.pdf Retreived on 17-06-2020.

21. Sogani RK, Sharma DK, Gupta V. Cardio-vascular collapse following small dose of chloroquine in healthy young adult. J Assoc Physicians India. 1986;34:534. 
22. Dogar MU, Shah NN, Ishtiaq S, Shah PN, Shah P, Mathew S, et al. Hydro chloroquine-induced restrictive cardiomyopathy: a case report. Post Grad Med J. 2018;94(1104):185-6.

23. Khubchandani SR, Bichle LS. Hydroxychloroquine induced phospholipidosis in a case of SLE: the wolf in Zebra clothing. Ultrastruct Pathol. 2013;37(2):146-50.

24. Pareek A, Chandurkar N, Thomas N, Viswanathan V, Deshpande A, Gupta OP, et al. Efficacy and safety of hydroxychloroquine in the treatment of type 2 diabetes mellitus: a double-blind, randomized comparison with pioglitazone. Curr Med Res Opin. 2014;30(7):1257-66.

25. Kubba S, Bali HK, Bahl A, Nand KS. Recurrent syncopal attacks in a lady with rheumatoid arthritis. J Postgrad Med. 2004;50:291-2.

26. Valecha N, Savargaonkar D, Srivastava B, Rao BH, Tripathi SK, Gogtay N, et al. Comparison of the safety and efficacy of fixed-dose combination of arterolane maleate and piperaquine phosphate with chloroquine in acute, uncomplicated Plasmodium vivax malaria: a phase III, multicentric, open-label study. Malar J. 2016;15(1):42.
27. Llanos-Cuentas A, Lacerda MV, Rueangweerayut R, Krudsood S, Gupta SK, Kochar SK, et al. Tafenoquine plus chloroquine for the treatment and relapse prevention of Plasmodium vivax malaria (DETECTIVE): a multicentre, double-blind, randomised, phase 2b dose-selection study. Lancet. 2014;383:1049-58.

28. Poravuth Y, Socheat D, Rueangweerayut R, Uthaisin C, Pyae Phyo A, Valecha N, et al. Pyronaridine-artesunate versus chloroquine in patients with acute Plasmodium vivax malaria: a randomized, double-blind, non-inferiority trial. PLoS One. 2011;6(1):e14501.

29. Kshirsagar NA, Gogtay NJ, Moorthy NS, Garg MR, Dalvi SS, Chogle AR, et al. A randomized, double blind, parallel group, comparative safety, and efficacy trial of co-artemether versus oral chloroquine in the treatment of acute uncomplicated Plasmodium falciparum malaria in adults in India. Am J Trop Med Hyg. 2000;62:402-8.

Publisher's Note Springer Nature remains neutral with regard to jurisdictional claims in published maps and institutional affiliations. 